\title{
Microstructural, Electrochemical and Localized Corrosion Characterization of the AA2198-T851 Alloy
}

\author{
João Victor de Sousa Araujo * (1), Rejane Maria Pereira da Silva ${ }^{a}$,Uyime Donatus ${ }^{a}$, \\ Caruline de Souza Carvalho Machado ${ }^{a}$, Isolda Costa ${ }^{a}$ \\ ${ }^{a}$ Instituto de Pesquisas Energeticas e Nucleares - IPEN, Centro de Ciência e Tecnologia de Materiais - \\ CNEN, São Paulo, SP, Brasil
}

Received: April 19, 2020; Revised: August 3, 2020; Accepted: August 4, 2020

\begin{abstract}
In the present work, the microstructure, electrochemical behavior and localized corrosion of the AA2198-T851 Al-Cu-Li alloy were studied. The microstructure was correlated with corrosion results obtained by immersion, gel visualization and scanning electrochemical microscopy (SECM) tests. Immersion and gel visualization tests showed high kinetics of corrosion attack during the first hours of immersion. SECM analyzes by means of surface generation/tip collection (SG/TC) mode detected hydrogen evolution generated during spontaneous corrosion from severe localized corrosion (SLC) sites on the metal surface. SECM results revealed sites of intense hydrogen evolution after $2 \mathrm{~h}$ of immersion and increased amounts of corrosion products after $4 \mathrm{~h}$ of immersion. Hydrogen evolution sites detected by SECM were associated with severe localized corrosion (SLC).
\end{abstract}

Keywords: Aluminum alloy, localized corrosion, hydrogen evolution, SLC, SECM.

\section{Introduction}

$\mathrm{Al}-\mathrm{Cu}-\mathrm{Li}$ alloys are high-performance materials employed in aircraft industry due to their characteristics (low density, high mechanical resistance, high tenacity, high-temperature resistance, weldability and good response to natural aging). In order to maximize and ensure those properties, processing of alloy needs to select accurately the thermomechanical processing routes and optimize the chemical composition ${ }^{1-6}$. This is important because the final microstructure of the alloy directly influences its performance.

Generally, the microstructure of Al alloys is composed of micro-sized and nano-sized particles, which are formed in distinct stages of processing. Micro-sized particles are formed during casting. Precipitation and distribution of the nanosized particles occurs during thermomechanical processes ${ }^{7}$. These particles present different contributions to the alloy mechanical properties: only the nano-sized particles contribute actively by improving the alloy mechanical resistance. Among all the possible nanometric phases present in the microstructure of Al-Cu-Li alloys, the $\mathrm{T} 1\left(\mathrm{Al}_{2} \mathrm{CuLi}\right)$ phase is the main hardening phase, which precipitates preferentially at dislocations and grain/subgrain boundaries. Consequently, a pre-deformation stage (stretching), before aging, can be added to the thermomechanical treatment in order to increase the dislocation density, introducing sites for nucleation of this phase ${ }^{8}$. Therefore, high level of deformation increases the number of dislocations leading to a high T1 phase density and improved mechanical resistance.

Despite the positive impact of T1 phase precipitation on the mechanical properties of the $\mathrm{Al}-\mathrm{Cu}-\mathrm{Li}$ alloys, corrosion studies have shown that the T1 phase adversely affects the

*email:joao-neutron@hotmail.com

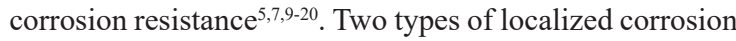
mechanisms have been associated with the Al-Cu-Li alloys. Micrometric particles affect the localized corrosion resulting in its partial dissolution and trenching ${ }^{10,21,22}$. The second one is the severe localized corrosion (SLC) associated with the T1 phase 7,10-13,18 $^{\text {. }}$

The mechanism and morphology of the SLC have been reported ${ }^{7,10}$. Buchheit et al. ${ }^{10}$ described that grain boundary attack is related to the preferential dissolution of $\mathrm{T} 1$ phase precipitated at subgrain boundaries. Ma et al. ${ }^{7}$ showed that SLC is characterized by hydrogen evolution and a cathodically protected area surrounding the anodic sites.

The effects of deformation on the corrosion behavior of Al-Cu-Li alloys have also been reported ${ }^{11,12,18,23,24}$. According to Guérin et al. ${ }^{18}$ grain boundaries with a high degree of atomic disarrangement/ misorientation are more reactive. Consequently, they are more susceptible to corrosion. On the other hand, subgrain boundaries with low energy present high resistance to corrosion. Thus, a galvanic coupling between grains with different internal misorientations led to corrosion at their interface. In addition, the preferential corrosion of grains oriented with the (111) planes suggested that galvanic coupling between grains with different orientations led to the preferential corrosion of some grains. Ma et al. ${ }^{25}$ studied the influence of thermomechanical treatments on the localized corrosion of $2099 \mathrm{Al}-\mathrm{Cu}-\mathrm{Li}$ alloy. The authors found that thermomechanical treatments influence susceptibility to SLC. The authors analyzed the samples in the T3, T6, and T8 temper conditions and found that the artificially aged alloy (T8) presented higher susceptibility to SLC than the other conditions analyzed. In another work, Ma et al. ${ }^{13}$ reported that localized corrosion tends to occur in grains with relatively 
large Schmid factor and related the corrosion mechanism to the selective dissolution of $\mathrm{T} 1$ phase preferentially precipitated at grain/subgrain boundaries and dislocations within grain interiors. Donatus et al. ${ }^{11}$ showed that the corrosion propagation mechanism in the AA2198-T851 occurs at specific grains and can be likened to the case of a slip mechanism through specific slip systems. Zhang et al. ${ }^{26}$ showed that the corrosion bands are parallel to the direction of needle-shaped T1 phase precipitates which have $\{111\}$ Al planes as the habit planes. Most recently, Zou et al. ${ }^{27}$ showed that the AA2198 alloy presented high corrosion resistance in different heat treatment conditions. These results are in agreement with those reported by Moreto et al. ${ }^{28}$ and Alexopoulos et al. ${ }^{29}$. In our previous publications ${ }^{12}$, the time-dependent susceptibility of the AA2198-T851 to SLC in $\mathrm{NaCl}$ solution was investigated by immersion and SVET tests. The results revealed that the propagation of SLC is crystallographic and associated with the slip bands in the individual grains of the alloy. The slip bands caused uneven precipitation of the active T1 particles. Oscillations in SVET current density values associated with the deposition and detachment of corrosion products were observed. The intensity of corrosion activities increased over time for open or partially covered pits.

In the present work, immersion, gel visualization tests, and scanning electrochemical microscopy (SECM) were employed to further add to the understanding of the local corrosion activities on the AA2198-T851 at different exposure times. SECM is a high-resolution scanning (well-established) technique to monitor in-situ corrosion processes through localized detection of electrochemically active species ${ }^{30-33}$. The SECM technique has been applied to study the local corrosion of aluminum alloys in different conditions $^{34-43}$. However, the use of SECM in conjunction with microstructural analysis to investigate the local corrosion processes associated to hydrogen evolution generated during spontaneous corrosion of new generation Al-Cu-Li alloys (AA2198-T851, in particular) is rare in the literature. Thus, this study contributes to the furtherance of the knowledge of corrosion behaviour of Al-Cu-Li alloys.

\section{Materials and Methods}

\subsection{Material}

The chemical composition of the AA2198-T851 used in this work is shown in Table 1. The T851 temper relates to solution heat treatment, stress relief by stretching, and artificial aging.

\subsection{Microstructural characterization}

Samples of the AA2198-T851 alloy were prepared to microstructural characterization by conventional metallographic techniques for microstructural characterization, immersion test, electrochemical experiments, and agar-agar gel visualization tests. The samples were ground with $\mathrm{SiC}$ papers (\#500,\#800,\#1200,\#4000) and polished with $3 \mu \mathrm{m}$ and $1 \mu \mathrm{m}$ diamond suspensions. The etching solution was composed of $2 \% \mathrm{HF}$ and $25 \% \mathrm{HNO}_{3}$ in deionized water. The surface examination was performed by optical microscopy (OM) using a Leica DMLM model microscope. Scanning Electron Microscopy (SEM) using a JEOL JSM-6010LA microscope mode equipped with energy dispersive X-ray spectroscopy (EDS) detectors was employed to analyze the micrometric particles. Moreover, a JEM-2100 transmission electron microscope (TEM), operating at $200 \mathrm{kV}$, was used to characterize the nanometric phases. Discs of $3 \mathrm{~mm}$ diameter were removed from alloy to produce samples used to perform TEM analysis. The discs were prepared by electrolytic polishing using a solution composed of $20 \%$ nitric acid in methanol at $25 \mathrm{~V}$ and $-30^{\circ} \mathrm{C}$. TenuPol equipment was used for this purpose. Microhardness tests were carried out using a TUKON 1202 WILSOI hardness tester with a load of $300 \mathrm{~g}$ for $10 \mathrm{~s}$. Thirty measurements were performed and the mean of the results was calculated.

\subsection{Immersion test}

The evolution of the corrosion sites was studied as a function of immersion time in $0.01 \mathrm{~mol} \mathrm{~L}^{-1} \mathrm{NaCl}$ solution by surface observation using a Leica DMLM optical microscope coupled to a Leica EC3 camera and controlled by a LAS ES software. After immersion test, the surface of the corroded sample was observed by scanning electron microscopy (SEM) using a TM Model 3000 in two different operation modes: backscattered electrons (BSE) and secondary electrons (SE).

\subsection{Agar-agar visualization}

A gel visualization technique was employed to detect the main anodic and cathodic sites on the alloy by means of $\mathrm{pH}$ variation due to corrosion activity ${ }^{44}$. A solution composed of $3 \mathrm{~g}$ of agar-agar in $100 \mathrm{~mL}$ of $0.7 \mathrm{~mol} \mathrm{~L}^{-1} \mathrm{NaCl}$ and $7 \mathrm{~mL}$ of universal $\mathrm{pH}$ indicator at $100{ }^{\circ} \mathrm{C}$ was used in the gel visualization assay, and then, a thin gel layer of about $1 \mathrm{~mm}$ to $2 \mathrm{~mm}$ in thickness was placed on the samples. Changes in the gel color and sample surfaces were monitored by observation as a function of time.

\subsection{Scanning electrochemical microscopy}

\section{(SECM): Instrumentation and measurement procedure}

Scanning electrochemical microscopy (SECM) was performed using a Sensolytics GmbH Bochum microscope. The experiments were performed at open circuit potential using a three electrode-cell experimental setup, with $25 \mu \mathrm{m} \mathrm{Pt}$ disk ultra-micro-electrode (Tip) as a working electrode, $\mathrm{Ag}$ / $\mathrm{AgCl} / \mathrm{KCl}$ (sat) as reference electrode and a platinum wire as the counter electrode. The exposed surface area of the sample (AA2198-T851 alloy) was $5 \mathrm{~mm}$. During the experiments the sample (alloy) was not polarized, thus it did not function as an electrode in the cell. The electrolyte used in the SECM

Table 1 - Chemical composition (wt\%) of the AA2198-T851 by Inductively Coupled Plasma - Atomic Emission Spectroscopy (ICP-AES ).

\begin{tabular}{cccccccccccc}
\hline Elements & $\mathbf{A l}$ & $\mathbf{C u}$ & $\mathbf{L i}$ & $\mathbf{M g}$ & $\mathbf{A g}$ & $\mathbf{Z r}$ & $\mathbf{F e}$ & $\mathbf{S i}$ & $\mathbf{Z n}$ & $\mathbf{M n}$ & $\mathbf{C u} / \mathbf{L i}$ \\
\hline $\mathbf{A A 2 1 9 8}-\mathbf{T 8 5 1}$ & 94.61 & 3.35 & 0.98 & 0.31 & 0.25 & 0.41 & 0.04 & 0.04 & 0.01 & - & 3.42 \\
\hline
\end{tabular}


tests was $0.01 \mathrm{~mol} \mathrm{~L}^{-1} \mathrm{NaCl}$ solution at $22 \pm 2{ }^{\circ} \mathrm{C}$. Samples used in the SECM test were observed by SEM prior to and after corrosion products removing. The process employed to remove the corrosion products was immersion in $30 \%$ $\mathrm{HNO}_{3}$ solution during $10 \mathrm{~s}^{7}$. Measurements were carried out at selected heights above the surface of Al-Cu-Li alloy. The operating height was set after recording $\mathrm{Z}$-approach curves in $0.005 \mathrm{~mol} \mathrm{~L}^{-1} \mathrm{NaCl}$ solution at a scan rate of $5 \mu \mathrm{m}$ $\mathrm{s}^{-1}$ using the redox competition SECM mode. In this SECM operating mode, tip and surface compete for the oxygen dissolved in solution. For this purpose, the tip potential was set at $-0.70 \mathrm{~V}$ vs. $\mathrm{Ag} / \mathrm{AgCl}$, and approximation curves were obtained by oxygen reduction in solution. Lower reductions current were obtained near the surface since the surface was consuming oxygen. Thus, a change in the profile of the limiting current was obtained when the tip has closed the surface. Tip-surface distance: $20 \mu \mathrm{m}$. More details about the redox competition SECM mode are provided in elsewhere ${ }^{45-47}$. SECM maps in constant height mode were obtained by scanning the Pt tip in the $x-y$ plane and recording the tip current as a function of tip location. The experiments were performed using the surface generation/tip collection (SG-TC) mode. In SG/TC mode, $\mathrm{H}_{2}$ generation from the corrosion activities on the surface is sensed as an oxidation reaction at the tip (reaction 1).

Reaction at the Tip: $\mathrm{H}_{2} \rightarrow 2 \mathrm{H}^{+}+2 \mathrm{e}^{-}$

Thus, $\mathrm{H}_{2}$ generation can be sensed in an oxidation reaction (1) at a $\mathrm{Pt}$ tip potential of $0 \mathrm{~V}$ versus $\mathrm{Ag} / \mathrm{AgCl}$. In the SG-TC mode, electroactive species on the surface can be oxidized or reduced at the microelectrode (tip), revealing electrochemically active sites on the surface ${ }^{30,31,48}$. In this mode, it is not necessary to introduce a redox mediator to detect electrochemical responses, and the selective detection of species on the surface involves the operation of the corroding cell in spontaneous conditions $\mathrm{s}^{31,48} . \mathrm{H}_{2}$ generation from the surfaces of different metal alloys has been investigated by SG-TC SECM mode ${ }^{23,49-55}$.

\section{Results and Discussion}

Figure 1a shows the grain morphology of the AA2198-T851 surface. The grains are equiaxed suggesting that recrystallization takes place, during the $\mathrm{T} 851$ treatment due to alloy deformation above of the cold working temperature ${ }^{56}$. A higher magnification image, as presented in Figure 1b, further reveals the presence of slip bands in certain grains (grain A contains slip bands while grains $\mathrm{B}$ and $\mathrm{C}$ have no slip bands). The slip bands are related to the stretching stage in the T851 thermomechanical processing ${ }^{57}$ and can be revealed after the preferential dissolution of $\mathrm{T} 1$ phaserich bands during etching (Figure 1 $\mathrm{a}$ and $\mathrm{b}$ ). Microhardness measurements revealed that grains with slip bands are harder $(209.1 \pm 7.4) \mathrm{HV}$ than grains without them $(183.4 \pm 4.64)$ HV. This difference was ascribed to additional sites for precipitation of T1 phase, such as slip bands. High amount of this phase is expected to precipitate in those grains, contributing to increase the hardness.

The nanometric $\mathrm{T} 1$ phase presents a thin needle morphology (Figure 2a) and its presence was confirmed by SAED pattern (Figure $2 b$ ), as reported in literature of similar $\mathrm{Al}-\mathrm{Cu}-\mathrm{Li}$ alloy ${ }^{58}$. It is formed during aging and precipitates at dislocations, subgrain/grain boundaries, and slip bands ${ }^{59}$. Besides, in a previous work ${ }^{60}$ DSC analyses showed that natural aging causes minor precipitation of $\mathrm{T} 1$ phase in $\mathrm{Al}-\mathrm{Li}$ alloys when compared with artificial aging. In other words, the T851 condition leads to a great amount of T1 phase precipitated during the fabrication process. Al-Cu-Li alloys also contain micrometric-sized Fe-containing constituent particles (CPs) as indicated in (Figure 2c). Usually, the $\mathrm{CPs}$ are aligned in deformation direction and have irregular morphologies $^{60}$. In this alloy, they are primarily composed of $\mathrm{Al}, \mathrm{Cu}$ and $\mathrm{Fe}$ (Figure 2d). Those particles are formed during casting ${ }^{61}$ due to the low solubility of iron in aluminum ${ }^{62}$, and do not improve mechanical properties of alloy.

The alloy mechanical properties are highly affected by the T1 phase. Figure 3 shows the development of corrosion on the surface of the AA2198-T851 during $24 \mathrm{~h}$. Two types of attacks, which present different features, can be seen on the
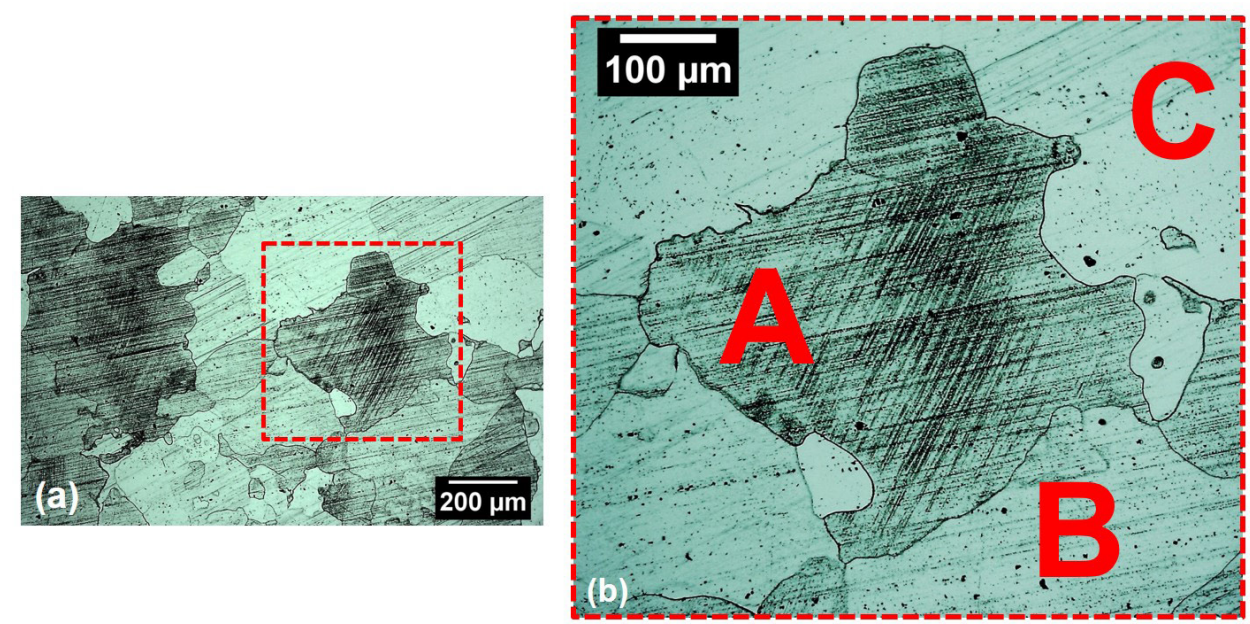

Figure 1. Optical micrographs showing (a) grain morphologies in the AA2198-T851; and (b) high magnification of the square region revealing grains with (A) and without (B) and (C) slip bands. 

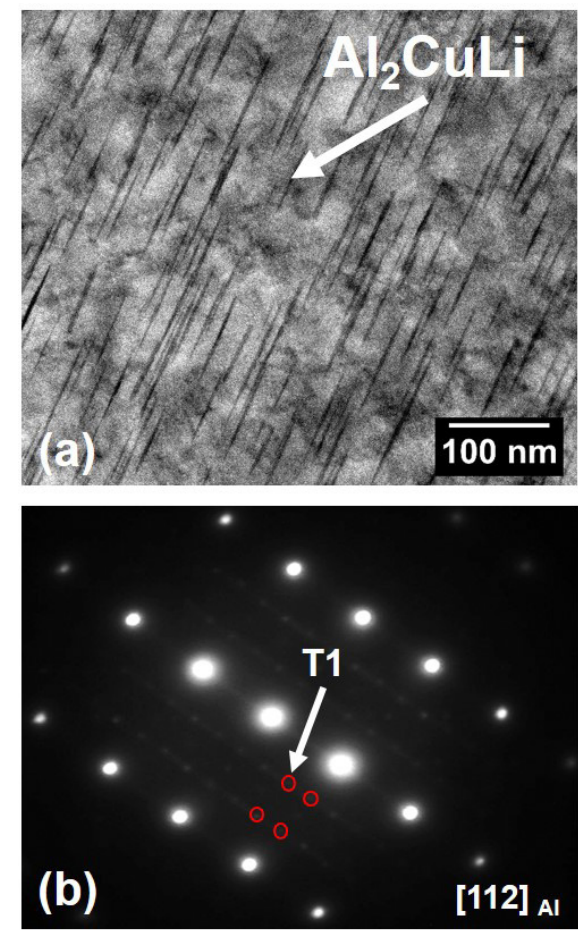
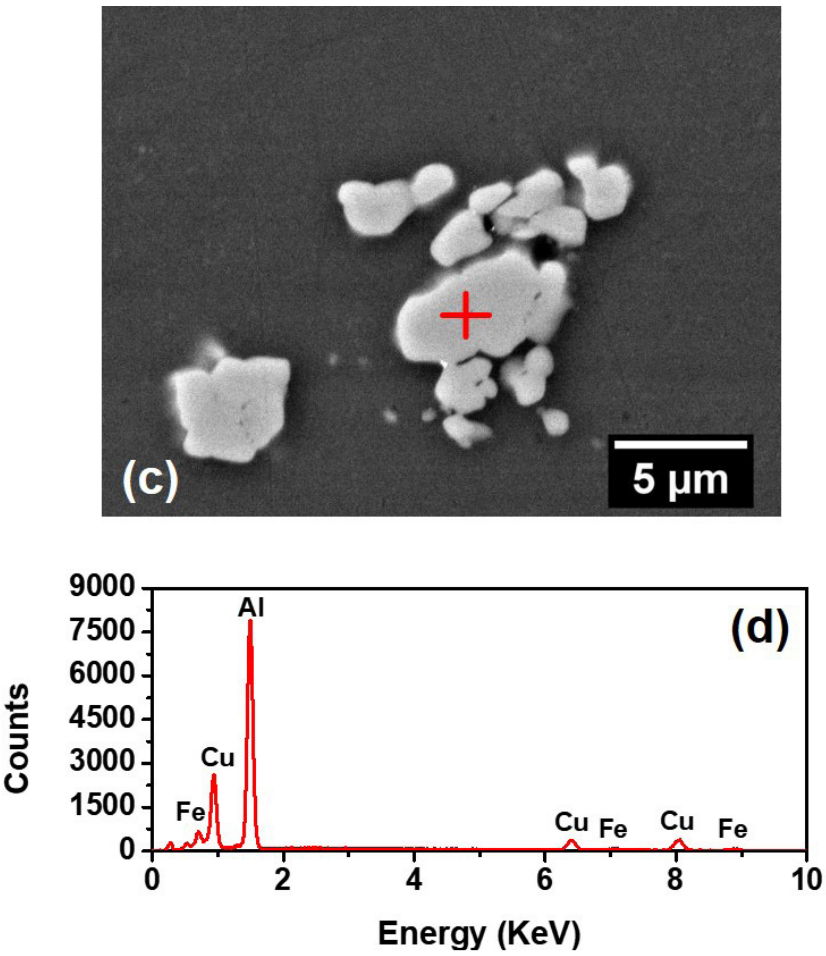

Figure 2. (a) Bright-field TEM micrographs of the AA2198 alloy showing T1 phase; (b) SAED pattern image near Al [101] zone axis; (c) SEM micrographs of the AA2198-T851 alloy surface showing constituent particles; and (d) EDS spectrum of the particle highlighted in Figure (c).
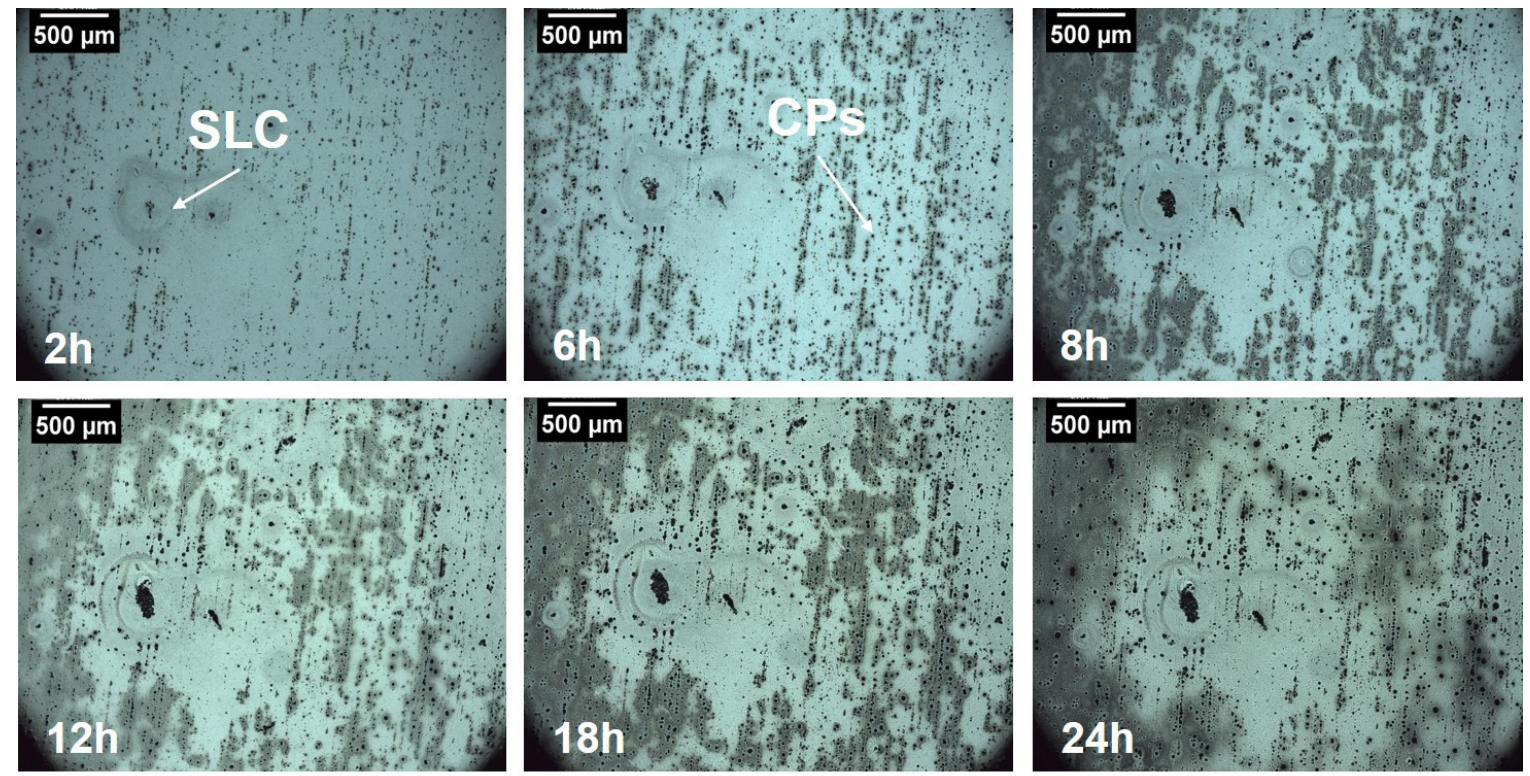

Figure 3. Optical micrographs of AA2198-T851 after several periods of immersion in $0.01 \mathrm{~mol} \mathrm{~L}^{-1} \mathrm{NaCl}$ solution.

surface. As indicated by arrows, one is associated with SLC, while the other is related to CPs. This last attack is detailed in Figure 4 and shows that it occurs around the particle (trenching). This type of attack causes surface discontinuity, as shown in the blue circle in Figure 4c.

Figure 5 shows the propagation mode of SLC in the AA2198-T851. The attack was preferentially in the stretching direction. The observed SLC propagation mode can be associated with the temper condition of the alloy. They are present due to the development of inhomogeneous plastic strains in high stacking fault energy materials such as Al-alloys ${ }^{63}$. In addition, they are characterized by the presence of dislocation accumulation in bands separated by relatively dislocation free regions ${ }^{64}$. The stretching 

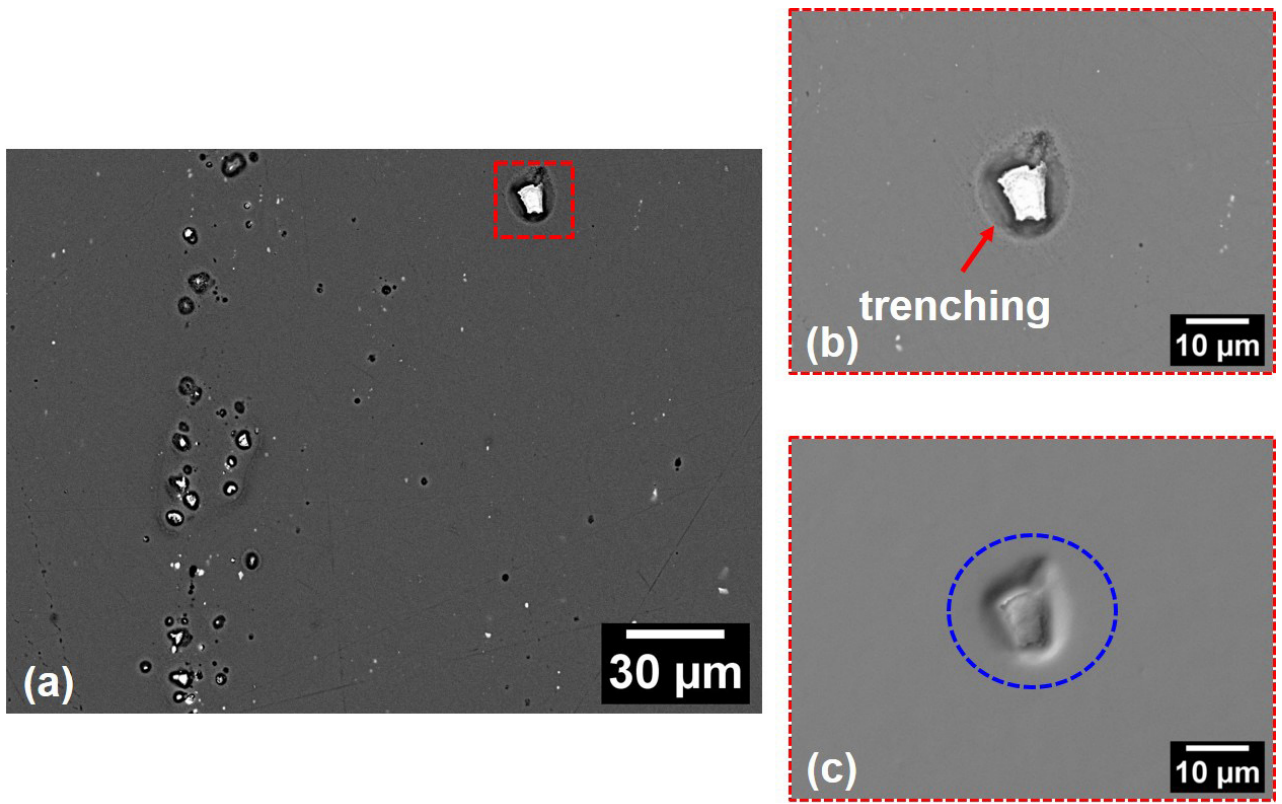

Figure 4. (a) SEM micrographs of the AA2198 - T851 after 24h of immersion in $0.01 \mathrm{~mol} \mathrm{~L}^{-1} \mathrm{NaCl}$ solution; (b) and (c) higher magnification images of the square region in (a) showing trenching around a constituent particle obtained by backscattered electrons (BSE) and secondary electrons (SE), respectively.
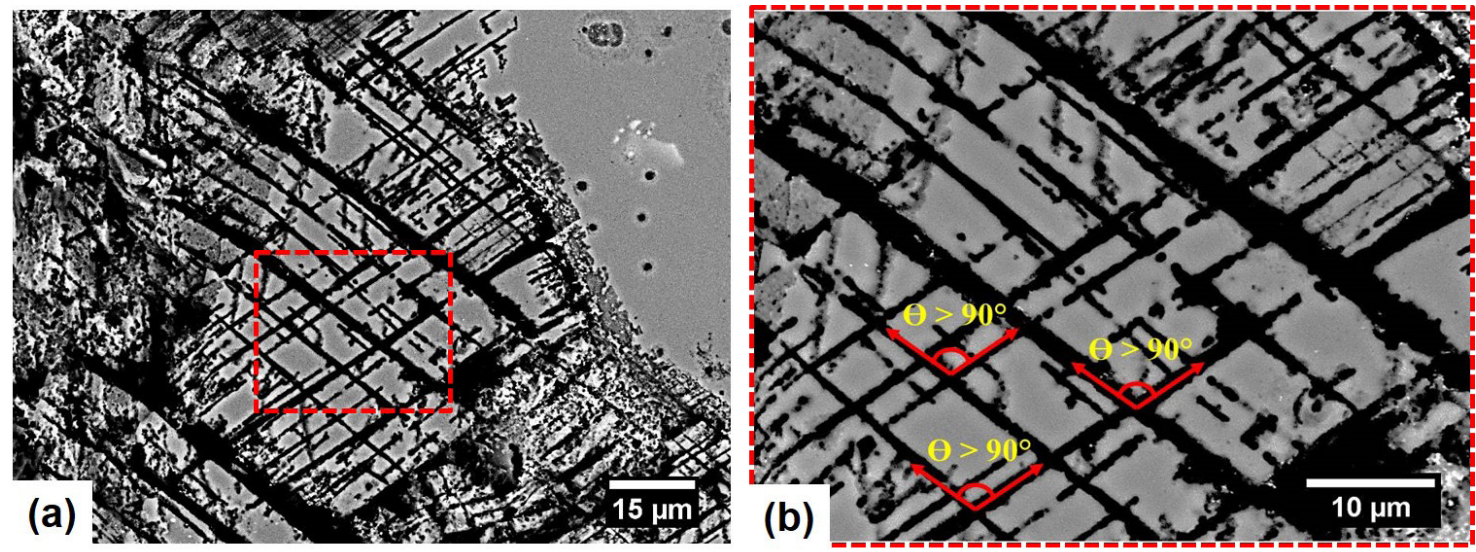

Figure 5. (a) Severe localized corrosion morphology in AA2198-T851. (b) Higher magnification image of the dashed square showing preferential attack at the slip bands (red arrows).

in T851 temper condition, prior to the artificial aging, is known to produce a great amount of dislocations within the grains ${ }^{11,28}$. As reported by Yin et al. ${ }^{65}$, dislocations are crystallographic defects where the atoms have deviated from the equilibrium state. The strain energy related to the lattice distortion results in high energy for diffusion and aggregation of solute atoms, favoring the nucleation of precipitates in the region of dislocations lines. In addition, the density of the precipitates in this region is higher and their size is smaller and finely distributed compared to the regions of the low density of this type of precipitate.

During immersion tests, bubble formation was observed in regions surrounding SLC sites, Figure 6a. The evolution of hydrogen, which occurs from the first hours of the test, is associated with the anodic regions where the formation of metallic cations promotes the hydrolysis of water. As a product of this reaction, the release of $\mathrm{H}^{+}$ions lead to a decrease in the local $\mathrm{pH}$. This technique has been described as a complementary test for the identification of localized corrosion sites due to local changes in $\mathrm{pH}^{66,67}$. Diffusion of ions generated by the electrochemical reactions is restrained because the gel allows low mobility; thus, they are maintained near to the anodic/cathodic sites. Therefore, the gel on the anodic regions changes color, becoming orange/yellow in the case of the indicator used in this study, due to the decrease in $\mathrm{pH}$ values as a result of the hydrolysis promoted by $\mathrm{Al}^{3+}$ ions, whereas the cathodic regions become blue/green due to $\mathrm{pH}$ increase as a result of the oxygen reduction reaction. Hence, the anodic and cathodic areas in this alloy are related to the SLC and trenching sites, respectively, as shown in 


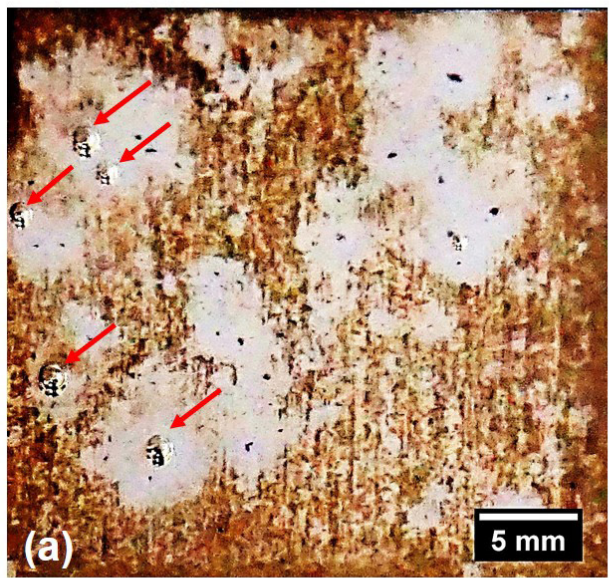

(b)
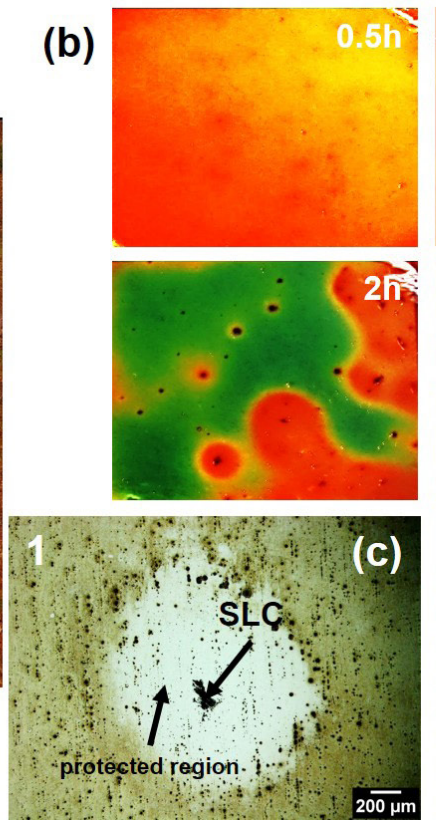
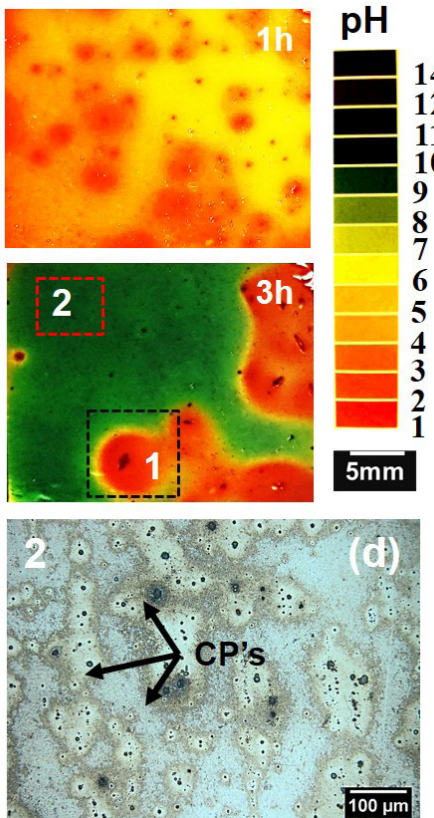

Figure 6. (a) Optical images of the AA2198-T851 after 4h immersion in $0.01 \mathrm{~mol} \mathrm{~L}^{-1} \mathrm{NaCl}$ solution; (b) Agar-agar visualization test of the AA2198-T851 at different periods of exposure to agar-agar gel containing $0.7 \mathrm{~mol} \mathrm{~L}^{-1} \mathrm{NaCl}$, showing the development of severe localized corrosion and its effect on the local $\mathrm{pH}$; (c) Severe localized corrosion (SLC) and cathodically protected region surrounding the pit/SLC; and (d) localized attack related to constituent particles in the AA2198-T851.

Figure $6 \mathrm{~b}$. Figure 6 also shows that $\mathrm{pH}$ largely decreases in the SLC region. As mentioned, acidification occurs mainly within pits and results in the evolution of hydrogen bubbles, Figure 6a. Due to low ionic mobility in agar-agar, the $\mathrm{pH}$ in the regions surrounding SLC sites decreases to very low values. SLC exhibits distinct characteristics ${ }^{12,57,68}$ from the localized attack that is associated with the microcells between the matrix and constituent particles, Figure $6 \mathrm{c}$ and $\mathrm{d}$. Besides, both attacks show different depths of penetration. Recent works ${ }^{60,69}$ have shown by optical profilometry results that a higher penetration depth for the SLC from the order of $30 \mu \mathrm{m}$ is observed when compared to trenching associated with the constituent particles. Areas, where localized attack occurred, were darkened by the corrosion products formed. The preferential dissolution of $\mathrm{Li}$ and $\mathrm{Al}$ ions from the $\mathrm{T} 1$ phase promotes hydrolysis and results in acidification of the medium and propagation of corrosion. In the interior of the pits associated with SLC, dilution of the inner solution is hampered ${ }^{60}$ which favors local acidification, as evidenced by the evolution of hydrogen during immersion test (Figure 6a), and, consequently, passivation is prevented. In this way, the potential difference between the outer and the inner surface of the SLC results in cathodic protection of the surrounding area, as shown in Figure 6c. The main reactions involved in the SLC, inside (2) and (3) and outside (4) the pits of SLC are given below:

$$
\begin{gathered}
\mathrm{Al} \rightarrow \mathrm{Al}^{3+}+3 \mathrm{e}^{-} \\
2 \mathrm{H}^{+}+2 \mathrm{e}^{-} \rightarrow \mathrm{H}_{2} \uparrow \\
\mathrm{Al}^{3+}+3 \mathrm{H}_{2} \mathrm{O} \rightarrow \mathrm{Al}(\mathrm{OH})_{3}+3 \mathrm{H}^{+}
\end{gathered}
$$

During the corrosion process, the oxidation of $\mathrm{Al}$ to $\mathrm{Al}^{3+}$ in the anodic regions (2) is promoted, which in turn promotes the hydrolysis of water (4) resulting in $\mathrm{pH}$ decrease, as well as favoring the evolution of the hydrogen gas (3). Therefore, bubbles of hydrogen are indicative of low $\mathrm{pH}$ and these have been associated with SLC sites. Thus, in these sites cathodic reactions occur inside anodic sites. This phenomenon was reported in some works ${ }^{70-72}$ with magnesium-based alloys, termed as negative difference effect (NDE). Also, Donatus et al. ${ }^{73}$ observed hydrogen evolution during anodic polarization when immersed in $3.5 \mathrm{wt}$. $\% \mathrm{NaCl}$ solution.

Hydrogen evolution was also confirmed during SECM experiments. Through this technique, it was possible to map the sites of hydrogen gas evolution generated during the spontaneous corrosion of the alloy and to associate these sites to SLC regions, as can be observed in Figure 7. The SECM maps of the AA2198-T851 surface, where the upper and lower color scales are an indication of different current intensities for hydrogen evolution from the surface. After 40 min of immersion, it was possible to observe that the surface was electrochemically active. After $2 \mathrm{~h}$ of immersion, significant hydrogen evolution with maximum oxidation current in the range of $40 \mathrm{nA}$ was observed, and after $4 \mathrm{~h}$ of immersion, a new site with hydrogen evolution was found. At this time, the buildup of corrosion products on the first SLC site seen led to a decrease in the current previously measured. The hydrogen $\left(\mathrm{H}_{2}\right)$ generated inside the pits was detected by the SECM tip polarized at $0 \mathrm{~V}$ that led to $\mathrm{H}_{2}$ oxidation on the tip (as shown in (1)). In a recent work from the our group ${ }^{68}$, it was shown that the polished surface of an $\mathrm{Al}-\mathrm{Cu}-\mathrm{Li}$ alloy developed pronounced SLC sites, and these sites were associated with hydrogen 
evolution on the surface of the alloy. Figure $8 \mathrm{~b}$ shows the alloy surface after the SECM test. It is possible to note that points 1 and 2 identified in the SECM maps were related to SLC (Figure 8a). From Figure 8c and d, it can be seen those corrosion products accumulated on the SLC site, but after their removal by desmutting (Figure 8e and $\mathrm{f}$ ) the depth of attack was revealed. This observation supported the proposal that corrosion products accumulated on the anodic sites led to decreased current values measured during the test. Thus, the accumulation of corrosion products play an important role in the local electrochemical measurements and also observed in a recent work ${ }^{12}$

Based on the microstructural features and the corrosion process, a corrosion mechanism was proposed for the formation of $\mathrm{H}_{2}$ related to SLC sites in the AA2198-T851 and its detection by SECM, Figure 9.

Figure 9a shows the typical microstructure of the 2198-T851. Since plastic deformation is not uniform, some grains will be more stressed than others. Assuming that grain A was more deformed than $\mathrm{B}$ and $\mathrm{C}$, it presents a higher density of the T1 phase than the others. When this surface is exposed to corrosive environments, grain A will be preferentially corroded. During the corrosion process, the T1 phase, initially anodic to the matrix, becomes cathodic due to the selective dissolution of $\mathrm{Al}$ and $\mathrm{Li}$ that results in a $\mathrm{Cu}$-rich remnant, causing an inversion of polarity ${ }^{74}$. Subsequently, the matrix is corroded and $\mathrm{Al}^{+3}$ is generated inside the pit, at the corrosion front Figure 9b. The penetration of SLC increases with time ${ }^{7,60,69}$, and differential aeration between the outer surface and the interior of the pit is favored. This further promotes hydrolysis by $\mathrm{Al}^{+3}$ ions and $\mathrm{H}^{+}$ions are produced inside the pits decreasing local $\mathrm{pH}$. This leads to $\mathrm{H}_{2}$ gas generation (Figures $7 \mathrm{a}$ and $\mathrm{b}$ ). The SECM tip detects the $\mathrm{H}_{2}$ gas generated, as shown the Figure 9c. $\mathrm{O}_{2}$ reduction occurs outside the SLC producing $\mathrm{OH}^{-}$and it combines with $\mathrm{Al}^{+3}$ ions resulting in the precipitation of corrosion product
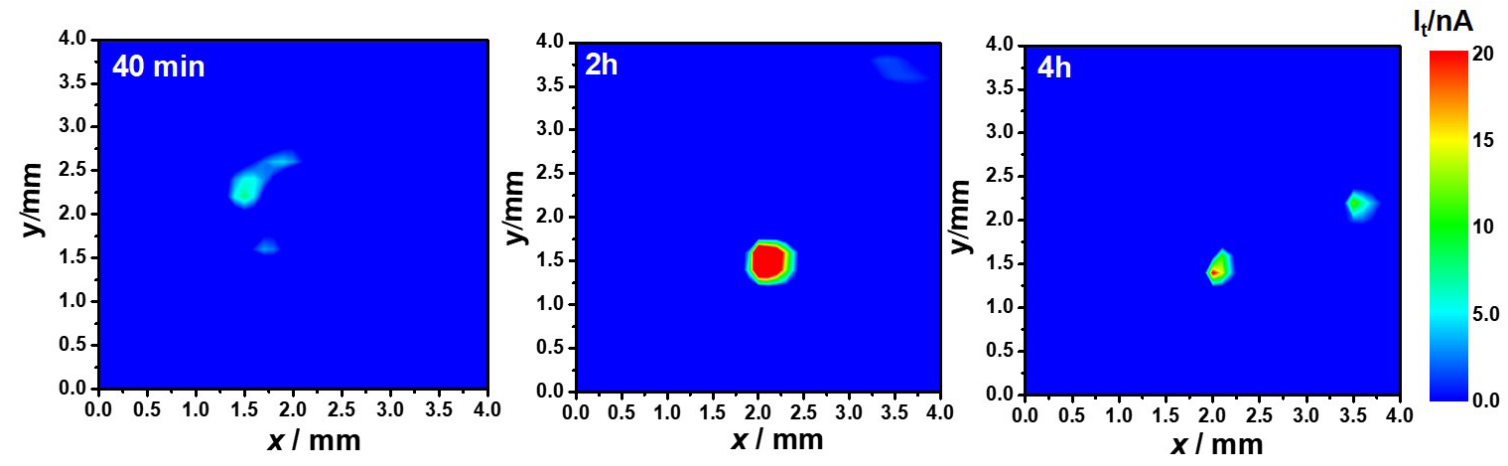

Figure 7. SECM hydrogen evolution (HE) maps for the AA2198-T851 immersed in $0.01 \mathrm{~mol} \mathrm{~L}^{-1} \mathrm{NaCl}$ solution.
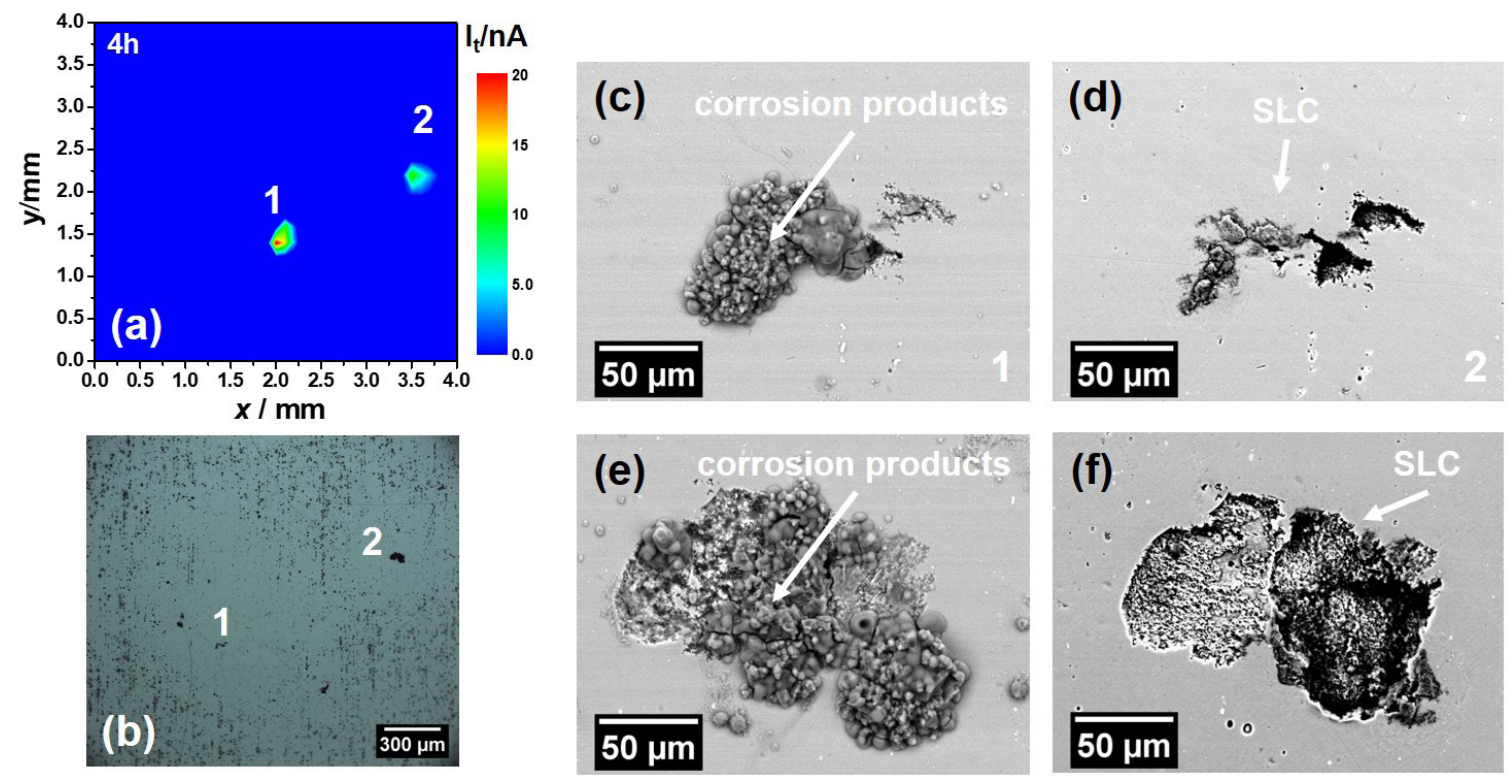

Figure 8. (a) SECM map of the surface of the AA2198-T851 after 4h of immersion in $0.01 \mathrm{~mol} \mathrm{~L}^{-1} \mathrm{NaCl}$ solution; (b) Optical micrograph of the alloy surface after test; (c)-(f) SEM micrographs of sites 1 and 2 associated with SLC (c) and (e) prior to desmutting and (d) and (f) after desmutting. 

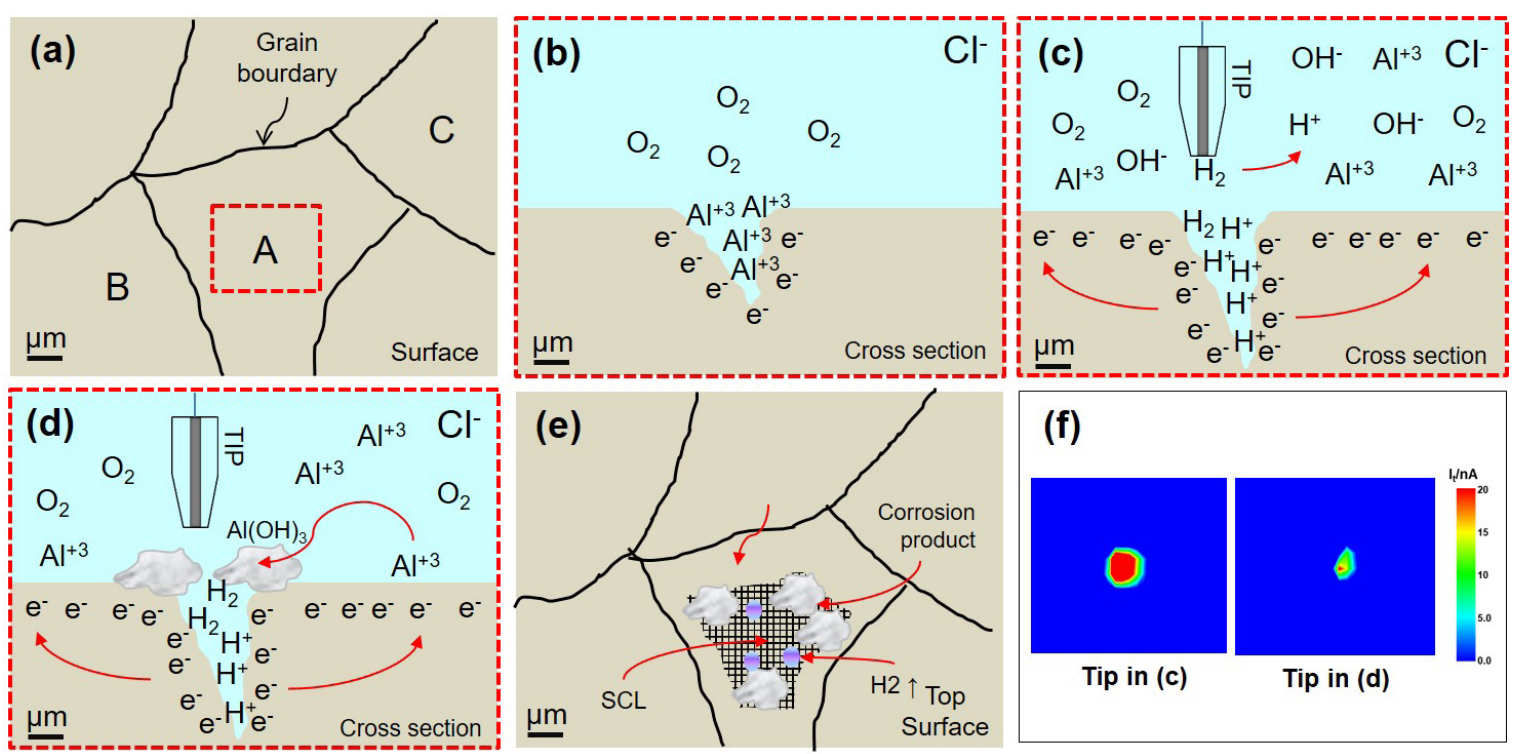

Figure 9. Schematic diagrams of the mechanism proposed for $\mathrm{H}_{2}$ evolution detection at severe localized corrosion sites in the AA2198-T851: (a) schematic of the alloy microstructure; (b) corrosion initiation attack; (c) detection of $\mathrm{H}_{2}$ gas; (d) corrosion products deposition; (e) development of SLC; and (f) SECM maps obtained in (c) and (d).

$\mathrm{Al}(\mathrm{OH})_{3}$ at the areas surrounding and at the pit/SLC "mouth" and the accumulation of corrosion products result in a decrease of corrosion currents being measured since $\mathrm{H}_{2}$ is trapped inside the pits/SLC (Figures 9d and e). Figure 9f shows the difference of the probe signal due to the formation of corrosion products, Figures $9 \mathrm{c}$ and d. Araujo et al. ${ }^{12}$ studied SLC evolution on the AA2198-T851 using scanning vibrating electrode technique (SVET). The authors verified that accumulation of corrosion products on SLC pits decreased the anodic current density values recorded over the pits, but the eventual detachment of these products resulted in increased current densities.

\section{Conclusions}

The AA2198-T851 studied presented high activity in low chloride concentrated media, showing susceptibility to corrosion. Immersion and gel visualization tests showed that the kinetics of the attack is fast since the first hours of immersion. SECM in the SG/TC mode detected pronounced hydrogen evolution sites on the AA2198-T851 surface after $2 \mathrm{~h}$ of immersion. SLC was associated with the hydrogen evolution on the surface of the alloy monitored by SECM. This technique proved to be useful to detect reactive sites during spontaneous corrosion of the AA2198-T851.

\section{Acknowledgment}

The authors are grateful to FAPESP (Process 2019/18388-1) for the grants of João Victor de Sousa Araujo for financial support for this research and the grants of Rejane M.P da Silva and U. Donatus (Procs. 2018/06880-6 and 2016/20572-7).

\section{References}

1. Rioja RJ, Liu J. The evolution of Al-Li base products for aerospace and space applications. Metall Mater Trans, A Phys
Metall Mater Sci. 2012;43(9):3325-37. http://dx.doi.org/10.1007/ s11661-012-1155-z.

2. Warner T. Recently-developed aluminium solutions for aerospace applications. Mater Sci Forum. 2006;1271:519-521.

3. Chen J, Madi Y, Morgeneyer TF, Besson J. Plastic flow and ductile rupture of a $2198 \mathrm{Al}-\mathrm{Cu}-\mathrm{Li}$ aluminum alloy. Comput Mater Sci. 2011;50(4):1365-71. http://dx.doi.org/10.1016/j. commatsci.2010.06.029.

4. Romios M, Tiraschi R, Parrish C, Babel HW, Ogren JR, Es-Said OS. Design of multistep aging treatments of 2099 (C458) Al-Li alloy. J Mater Eng Perform. 2005;14(5):641-6. http://dx.doi. org/10.1361/105994905X64594.

5. Mishra S, Beura VK, Singh A, Yadava M, Nayan N. Deformation behaviour of $\mathrm{Al}-\mathrm{Cu}-\mathrm{Li}$ alloy containing $\mathrm{T} 1$ precipitates deformation behaviour of $\mathrm{AlCu}-\mathrm{Li}$ alloy containing $\mathrm{T} 1$ precipitates. Mater Sci Technol. 2018;34(17):1-9. http://dx.doi.org/10.1080/02670836.2 018.1510074.

6. Lin Y, Lu C, Wei C, Zheng Z. Influences of friction stir welding and post-weld heat treatment on Al-Cu-Li Alloy. Adv Eng Mater. 2018;20(2):1-8. http://dx.doi.org/10.1002/adem.201700652.

7. Ma Y, Zhou X, Huang W, Thompson GE, Zhang X, Luo C, et al. Localized corrosion in AA2099-T83 aluminum-lithium alloy: the role of intermetallic particles. Mater Chem Phys. 2015;161:201-10. http://dx.doi.org/10.1016/j.matchemphys.2015.05.037.

8. Benedyk JC. International temper designation systems for wrought aluminium alloys. Part II - thermally treated (t temper) aluminium alloys. Light Metal Age 2010: 16-22.

9. KertzEJ, Gouma PI, Buchheit RG. Localized corrosion susceptibility of Al-Li-Cu-Mg-Zn alloy AF/C458 due to interrupted quenching from solutionizing temperature. Metall Mater Trans, A Phys Metall Mater Sci. 2011;32(10):2561-73. http://dx.doi.org/10.1007/s11661001-0046-5.

10. Buchheit RG Jr, Moran JP, Stoner GE. Localized corrosion behavior of aiioy 2090: the role of microstructural heterogeneity. Corrosion. 1990;46(8):610-7. http://dx.doi.org/10.5006/1.3585156.

11. Donatus U, Terada M, Ospina CR, Queiroz FM, Bugarin AFS, Costa I. On the AA2198-T851 alloy microstructure and its correlation with localized corrosion behaviour. Corros Sci. 2018;131(300):300-9. http://dx.doi.org/10.1016/j.corsci.2017.12.001. 
12. Araujo JVS, Donatus U, Queiroz FM, Terada M, Milagre MX, Alencar MC, et al. On the severe localized corrosion susceptibility of the AA2198-T851 alloy. Corros Sci. 2018;133:132-40. http:// dx.doi.org/10.1016/j.corsci.2018.01.028.

13. Ma Y, Zhou X, Liao Y, Yi Y, Wu H, Wang Z, et al. Localised corrosion in AA 2099-T83 aluminium-lithium alloy: the role of grain orientation. Corros Sci. 2016;107:41-8. http://dx.doi. org/10.1016/j.corsci.2016.02.018.

14. Ma Y, Zhou X, Thompson GE, Curioni M, Skeldon P, Zhang $\mathrm{X}$, et al. Anodic film growth on Al-Li-Cu alloy AA2099-T8. Electrochim Acta. 2012;80:148-59. http://dx.doi.org/10.1016/j. electacta.2012.06.126.

15. Ma Y, Zhou X, Thompson GE, Curioni M, Hashimoto T, Skeldon P, et al. Anodic film formation on AA 2099-T8 aluminum alloy in tartaric-sulfuric acid. J Electrochem Soc. 2011;158(2):17-22. http://dx.doi.org/10.1149/1.3523262.

16. Ma Y, Zhou X, Thompson GE, Curioni M, Zhong X, Koroleva E, et al. Discontinuities in the porous anodic film formed on AA2099-T8 aluminium alloy. Corros Sci. 2011;53(12):4141-51. http://dx.doi.org/10.1016/j.corsci.2011.08.023.

17. Ma Y, Zhou X, Thompson GE, Skeldon P. Surface texture formed on AA2099 Al-Li-Cu alloy during alkaline etching. Corros Sci. 2013;66:292-9. http://dx.doi.org/10.1016/j.corsci.2012.09.032.

18. Guérin M, Alexis J, Andrieu E, Laffont L, Lefebvre W, Odemer $\mathrm{G}$, et al. Identification of the metallurgical parameters explaining the corrosion susceptibility in a 2050 aluminium alloy. Corros Sci. 2016;102:291-300. http://dx.doi.org/10.1016/j.corsci.2015.10.020.

19. Guérin M, Alexis J, Andrieu E, Blanc C, Odemer G. Corrosionfatigue lifetime of Aluminium-Copper-Lithium alloy 2050 in chloride solution. Mater Des. 2015;87:681-92. http://dx.doi. org/10.1016/j.matdes.2015.08.003.

20. Proton V, Alexis J, Andrieu E, Delfosse JO, Deschamps A, Geuser $\mathrm{FD}$, et al. The influence of artificial ageing on the corrosion behaviour of a 2050 aluminium-copper-lithium alloy. Corros Sci. 2014;80:494-502. http://dx.doi.org/10.1016/j.corsci.2013.11.060.

21. Grilli R, Baker MA, Castle JE, Dunn B, Watts JF. Localized corrosion of a 2219 aluminium alloy exposed to a $3.5 \% \mathrm{NaCl}$ solution. Corros Sci. 2010;52(9):2855-66. http://dx.doi.org/10.1016/j. corsci.2010.04.035.

22. Luo C, Zhang X, Zhou X, Sun Z, Zhang X, Tang Z, et al. Characterization of localized corrosion in an Al-Cu-Li Alloy. J Mater Eng Perform. 2016;25(5):1811-9. http://dx.doi.org/10.1007/ s11665-016-2010-y.

23. Milagre MX, Donatus U, Machado CSC, Araujo JVS, Silva RMP, Viveiros BVG, et al. Comparison of the corrosion resistance of an Al-Cu alloy and an Al-Cu-Li alloy. Corros Eng Sci Technol. 2019;54(5):402-12. http://dx.doi.org/10.1080/1478422X.2019.1605472.

24. Moreto JA, Broday EE, Rossino LS, Fernandes JCS, Bose WW Fo. Effect of localized corrosion on fatigue-crack growth in 2524T3 and 2198-T851 aluminum alloys used as aircraft materials. J Mater Eng Perform. 2018;27(4):1917-26. http://dx.doi.org/10.1007/ s11665-018-3244-7.

25. Ma Y, Zhou X, Meng X, Huang W, Liao Y, Chen X, et al. Influence of thermomechanical treatments on localized corrosion susceptibility and propagation mechanism of AA2099 Al-Li alloy. Trans Nonferrous Met Soc China. 2016;26(6):1472-81. http:// dx.doi.org/10.1016/S1003-6326(16)64252-8.

26. Zhang X, Zhou X, Hashimoto T, Liu B, Luo C, Sun Z, et al. Corrosion behaviour of 2A97-T6 Al-Cu-Li alloy: the influence of non-uniform precipitation. Corros Sci. 2018;132:1-8. http:// dx.doi.org/10.1016/j.corsci.2017.12.010.

27. Zou Y, Chen X, Chen B. Corrosion behavior of $2198 \mathrm{Al}-\mathrm{Cu}-\mathrm{Li}$ alloy in different aging stages in $3.5 \mathrm{wt} \% \mathrm{NaCl}$ aqueous solution. J Mater Res. 2018;33(2):1011-22. http://dx.doi.org/10.1557/ jmr.2018.33.

28. Moreto JA, Marino CEB, Bose WW Fo, Rocha LA, Fernandes JCS. SVET, SKP and EIS study of the corrosion behaviour of high strength $\mathrm{Al}$ and $\mathrm{Al}-\mathrm{Li}$ alloys used in aircraft fabrication. Corros Sci. 2014;84:30-41. http://dx.doi.org/10.1016/j.corsci.2014.03.001.

29. Alexopoulos ND, Proiou A, Dietzel W, Blawert C, Heitmann $\mathrm{V}$, Zheludkevich $\mathrm{M}$, et al. Mechanical properties degradation of (Al-Cu-Li) 2198 alloy due to corrosion exposure. Procedia Structural Integrity. 2016;2:597-603. http://dx.doi.org/10.1016/j. prostr.2016.06.077.

30. Bard AJ, Fan FRJ, Kwak J, Lev O. Scanning electrochemical microscopy. introduction and principles. Anal Chem. 1989;61(24):1328. http://dx.doi.org/10.1021/ac00177a011.

31. Souto RM, Lamaka SV, González S. Uses of scanning electrochemical microscopy in corrosion research. In: Méndez-Vilas A, Díaz J, editors. Microscopy: science, technology, applications and education (Vol. 3, pp. 1769-80). Badajoz: Formatex Research Center; 2010.

32. Santana JJ, González S, Izquierdo J, Souto RM. Applications of scanning electrochemical microscopy (SECM) for the investigation of local corrosion processes. Afinidad. 2011;68:44-9.

33. Senöz C, Maljusch A, Rohwerder M, Schuhmann W. SECM and SKPFM studies of the local corrosion mechanism of al alloys: a pathway to an integrated SKP-SECM system. Electroanalysis. 2012;24(2):239-45. http://dx.doi.org/10.1002/elan.201100609.

34. Carbonell DJ, García-Casas A, Izquierdo J, Souto RM, Galván JC, Jiménez-Morales A. Scanning electrochemical microscopy characterization of sol-gel coatings applied on AA2024-T3 substrate for corrosion protection. Corros Sci. 2016;111:625-36. http://dx.doi.org/10.1016/j.corsci.2016.06.002.

35. Davoodi A, Pan J, Leygraf C, Norgren S. The role of intermetallic particles in localized corrosion of an aluminum alloy studied by SKPFM and Integrated AFM/SECM. J Electrochem Soc. 2008;155(5):211-8. http://dx.doi.org/10.1149/1.2883737.

36. Izquierdo J, González S, Souto RM. Application of AC-SECM in corrosion science: local visualization of heterogeneous chemical activity in AA2024 surfaces. Int J Electrochem Sci. 2012;7(11):1137788.

37. Lafouresse MC, Bonfils-Lahovary M-L, Laffont L, Blanc C. Hydrogen mapping in an aluminum alloy using an alternating current scanning electrochemical microscope (AC-SECM). Electrochem Commun. 2017;80:29-32. http://dx.doi.org/10.1016/j. elecom.2017.05.007.

38. Jensen BM, Guerard A, Tallman DE, Bierwagen GP. Studies of electron transfer at aluminum alloy surfaces by scanning electrochemical microscopy. J Electrochem Soc. 2008;155(7):32434. http://dx.doi.org/10.1149/1.2916734.

39. Liu W, Singh A, Lin Y, Ebenso EE, Tianhan G, Ren C. Corrosion inhibition of Al-alloy in 3.5\% NaCl solution by a natural inhibitor: an electrochemical and surface study. Int J Electrochem Sci. 2014;9(10):5560-73.

40. Recloux I, Gonzalez-Garcia Y, Druart M, Khelifa F, Dubois P, Mol JMC, et al. Surface \& coatings technology active and passive protection of AA2024-T3 by a hybrid inhibitor doped mesoporous sol-gel and top coating system. Surf Coat Tech. 2015;303:352-61. http://dx.doi.org/10.1016/j.surfcoat.2015.11.002.

41. Sidane D, Bousquet E, Devos O, Puiggali M, Touzet M, Vivier $\mathrm{V}$, et al. Local electrochemical study of friction stir welded aluminum alloy assembly. J Electroanal Chem. 2014;737:206-11. http://dx.doi.org/10.1016/j.jelechem.2014.06.025.

42. Seegmiller JC, Buttry DA. A SECM Study of Heterogeneous Redox Activity at AA2024 Surfaces. J Electrochem Soc. 2003;150(9):41320. http://dx.doi.org/10.1149/1.1593041.

43. Zhou H, Li X, Dong C, Xiao K, Li T. Corrosion behavior of aluminum alloys in $\mathrm{Na}_{2} \mathrm{SO}_{4}$ solution using the scanning electrochemical microscopy technique. Int J Miner Metall Mater. 2009;16(1):84-8. http://dx.doi.org/10.1016/S1674-4799(09)60014-5.

44. Abreu CP, Costa I, Melo HG, Pébère N, Tribollet B, Vivier V. Multiscale Electrochemical Study of Welded Al Alloys Joined by Friction Stir Welding. J Electrochem Soc. 2017;164(13):735-48. http://dx.doi.org/10.1149/2.0391713jes. 
45. Bastos AC, Simões AM, González S, González-García Y, Souto $\mathrm{RM}$. Imaging concentration profiles of redox-active species in open-circuit corrosion processes with the scanning electrochemical microscope. Electrochem Commun. 2004;6(11):1212-5. http:// dx.doi.org/10.1016/j.elecom.2004.09.022.

46. Souto RM, González-García Y, González S. In situ monitoring of electroactive species by using the scanning electrochemical microscope: application to the investigation of degradation processes at defective coated metals. Corros Sci. 2005;47(12):3312-23. http:// dx.doi.org/10.1016/j.corsci.2005.07.005.

47. Souto RM, Fernández-Mérida LC, González S. SECM Imaging of Interfacial Processes in Defective Organic Coatings Applied on Metallic Substrates Using Oxygen as Redox Mediator. Electroanalysis. 2009;21(24):2640-6. http://dx.doi.org/10.1002/ elan.200900232.

48. Thomas S, Izquierdo J, Birbilis N, Souto RM. Possibilities and Limitations of Scanning Electrochemical Microscopy of $\mathrm{Mg}$ and Mg Alloys. Corrosion. 2015;71(2):171-83. http://dx.doi. org/10.5006/1483.

49. Tefashe UM, Snowden ME, Ducharme PD, Danaie M, Botton GA, Mauzeroll J. Local flux of hydrogen from magnesium alloy corrosion investigated by scanning electrochemical microscopy. J Electroanal Chem. 2014;720:121-7. http://dx.doi.org/10.1016/j. jelechem.2014.03.002.

50. Dauphin-Ducharme P, Matthew Asmussen R, Tefashe UM, Danaie M, Jeffrey Binns W, Jakupi P, et al. Local hydrogen fluxes correlated to microstructural features of a corroding sand Cast AM50 magnesium alloy. J Electrochem Soc. 2014;161(12):55764. http://dx.doi.org/10.1149/2.0571412jes.

51. Jamali SS, Moulton SE, Tallman DE, Forsyth M, Weber J, Wallace GG. Evaluating the corrosion behaviour of Magnesium alloy in simulated biological fluid by using SECM to detect hydrogen evolution. Electrochim Acta. 2015;152:294-301. http://dx.doi. org/10.1016/j.electacta.2014.11.012.

52. Jamali SS, Moulton SE, Tallman DE, Forsyth M, Weber J, Wallace GG. Applications of scanning electrochemical microscopy (SECM) for local characterization of AZ31 surface during corrosion in a buffered media. Corros Sci. 2014;86:93-100. http://dx.doi. org/10.1016/j.corsci.2014.04.035.

53. Mena-Morcillo E, Veleva L, Wipf DO. In situ investigation of the initial stages of AZ91D magnesium alloy biodegradation in simulated body fluid. Int J Electrochem Sci. 2018;13:5141-50. http://dx.doi.org/10.20964/2018.06.47.

54. Izquierdo J, Fernández-Pérez BM, Filotás D, Öri Z, Kiss A, Martín-Gómez RT, et al. Imaging of concentration distributions and hydrogen evolution on corroding magnesium exposed to aqueous environments using scanning electrochemical microscopy. Electroanalysis. 2016;28(10):2354-66. http://dx.doi.org/10.1002/ elan.201600265.

55. Silva RPM, Milagre MX, Oliveira LA, Donatus U, Antunes RA, Costa I. The local electrochemical behavior of the AA2098-T351 and surface preparation effects investigated by scanning electrochemical microscopy. Surf Interface Anal. 2019;51(10):982-92. http://dx.doi. org/10.1002/sia.6682.

56. Gable BM, Zhu AW, Csontos AA, Starke EAJ Jr. The role of plastic deformation on the competitive microstructural evolution and mechanical properties of a novel Al-Cu-Li-X alloy. J Light Met. 2001;1(14):1-14. http://dx.doi.org/10.1016/S1471-5317(00)00002-X.

57. Huang W, Ma Y, Zhou X, Meng X, Liao Y, Chai L, et al. Correlation between localized plastic deformation and localized corrosion in AA2099 aluminum-lithium alloy. Surf Interface Anal. 2016;48(8):838-42. http://dx.doi.org/10.1002/sia.5817.

58. Milagre MX, Mogili NV, Donatus U, Giorjão RAR, Terada M, Araujo JVS, et al. On the microstructure characterization of the AA2098-T351 alloy welded by FSW. Mater Charact. 2018;140:23346. http://dx.doi.org/10.1016/j.matchar.2018.04.015.

59. Lv K, Zhu C, Zheng J, Wang X, Chen B. Precipitation of T1 phase in $2198 \mathrm{Al}-\mathrm{Li}$ alloy studied by atomic-resolution HAADF-STEM.
J Mater Res. 2019;34(20):3535-44. http://dx.doi.org/10.1557/ jmr.2019.136.

60. Araujo JVS, Bugarin AFS, Donatus U, Machado CSC, Queiroz FM, Terada M, et al. Thermomechanical treatment and corrosion resistance correlation in the AA2198 Al-Cu-Li alloy. Corros Eng Sci Technol. 2019;54(7):575-86. http://dx.doi.org/10.1080/1478 422X.2019.1637077.

61. Birbilis N, Buchheit RG. Electrochemical characteristics of intermetallic phases in aluminum alloys: an experimental survey and discussion. J Electrochem Soc. 2005;152(4):140-51. http:// dx.doi.org/10.1149/1.1869984

62. Ma Y, Zhou X, Thompson GE, Hashimoto T, Thomson P, Fowles M. Distribution of intermetallics in an AA 2099-T8 aluminium alloy extrusion. Mater Chem Phys. 2011;126(1):46-53. http:// dx.doi.org/10.1016/j.matchemphys.2010.12.014.

63. Grosskreutz JG. The mechanisms of metal fatigue(II). Phys Status Solidi, B Basic Res. 1971;47(2):359-96. http://dx.doi.org/10.1002/ pssb.2220470202.

64. Al-Rubaie KS, Del Grande MA, Travessa DN, Cardoso KR. Effect of pre-strain on the fatigue life of 7050-T7451 aluminium alloy. Mater Sci Eng A. 2007;464(1):141-50. http://dx.doi.org/10.1016/j. msea.2007.02.024.

65. Yin D, Xiao Q, Chen Y, Liu H, Yi D, Wang B, et al. Effect of natural ageing and pre-straining on the hardening behaviour and microstructural response during artificial ageing of an Al-Mg-SiCu alloy. Mater Des. 2016;95:329-39. http://dx.doi.org/10.1016/j. matdes.2016.01.119.

66. Jariyaboon M, Davenport AJ, Ambat R, Connolly BJ, Williams SW, Price DA. The effect of welding parameters on the corrosion behaviour of friction stir welded AA2024-T351. Corros Sci. 2007;49(2):877-909. http://dx.doi.org/10.1016/j.corsci.2006.05.038.

67. Queiroz FM, Donatus U, Ramirez OMP, Araujo JVS, Viveiros BVG, Lamaka S, et al. Effect of unequal levels of deformation and fragmentation on the electrochemical response of friction stir welded AA2024-T3 alloy. Electrochim Acta. 2019;313:271-81. http://dx.doi.org/10.1016/j.electacta.2019.04.137.

68. Donatus U, Araujo JVS, Machado CSC, Mogili NVV, Antunes RA, Costa I. The effect of manufacturing process induced near-surface deformed layer on the corrosion behaviour of AA2198-T851 Al$\mathrm{Cu}-\mathrm{Li}$ alloy. Corros Eng Sci Technol. 2018;54(3):205-15. http:// dx.doi.org/10.1080/1478422X.2018.1558932.

69. Lei X, Saatchi A, Ghanbari E, Dang R, Li W, Wang N, et al. Studies on pitting corrosion of Al-Cu-Li Alloys part I: effect of $\mathrm{Li}$ Addition by microstructural, electrochemical, in-situ, and pit depth analysis. Materials. 2019;12(10):1-16. http://dx.doi.org/10.3390/ ma12101600. PMid:31100787.

70. Thomaz TR, Weber CR, Pelegrini T Jr, Dick LFP, Knörnschild G. The negative difference effect of magnesium and of the AZ91 alloy in chloride and stannate-containing solutions. Corros Sci. 2010;52(7):2235-43. http://dx.doi.org/10.1016/j.corsci.2010.03.010.

71. Weber CR, Knörnschild G, Dick LFP. The negative-difference effect during the localized corrosion of magnesium and of the AZ91HP alloy. J Braz Chem Soc. 2003;14(4):584-93. http://dx.doi. org/10.1590/S0103-50532003000400015.

72. Singh IB, Singh M, Das S. A comparative corrosion behavior of $\mathrm{Mg}, \mathrm{AZ31}$ and AZ91 alloys in $3.5 \% \mathrm{NaCl}$ solution. Journal of Magnesium and Alloys. 2015;3(2):142-8. http://dx.doi.org/10.1016/j. jma.2015.02.004.

73. Donatus U, Berbel LO, Costa I. Qualitative use of potentiodynamic polarization and anodic hydrogen evolution in the assessment of corrosion susceptibility in AA2198-T851 Al-Cu-Li alloy. Materials and Corrosion. 2018;69(10):1375-1388. http://dx.doi. org/10.1002/maco.201810108.

74. Li JF, Li CX, Peng ZW, Chen JW, Zheng ZQ. Corrosion mechanism associated with $\mathrm{T} 1$ and $\mathrm{T} 2$ precipitates of $\mathrm{Al}-\mathrm{Cu}-\mathrm{Li}$ alloys in $\mathrm{NaCl}$ solution. J Alloys Compd. 2008;460(2):688-93. http://dx.doi.org/10.1016/j.jallcom.2007.06.072. 